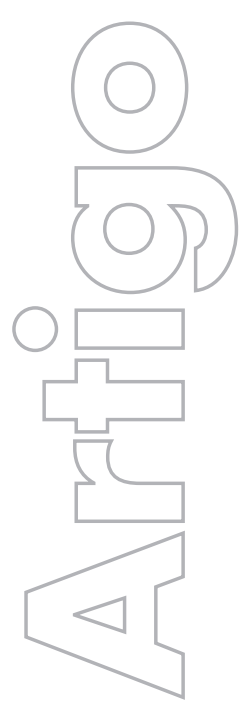

revista

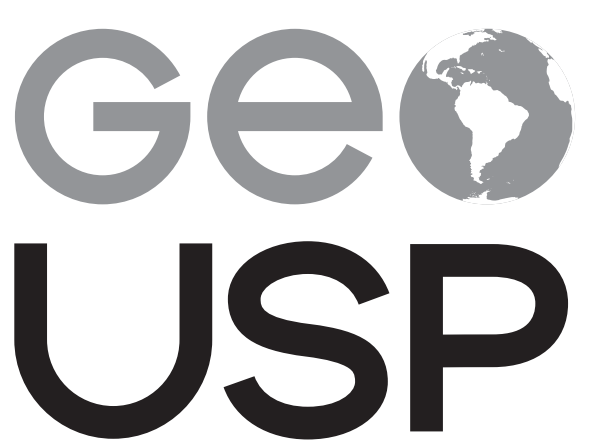

espaço e tempo

Volume $22 \cdot n^{\circ} 1(2018)$

\section{Terra indígena Foxá} "aqui no cedro": passado e presente Kaingang na sociedade do Vale do Taquari-RS-BR

\section{Emelí Lappe}

Centro Universitário Univates

Luís Fernando da Silva Laroque

Centro Universitário Univates

p. $025-042$

Como citar este artigo:

LAPPE, E.; LAROQUE, L. F. S. Terra indígena Foxá "aqui no cedro": passado e presente Kaingang na sociedade do Vale do Taquari-RS-BR. Geousp - Espaço e Tempo (Online), v. 22, n. 1, p. 025-042, mês. 2018. ISSN 2179-0892.

Disponível em: <http://www.revistas.usp.br/geousp/article/ view/125928>. doi: http://dx.doi.org/10.11606/issn.2179-0892. geousp.2018.125928.

\section{(c) (i) (8)}

Este artigo está licenciado sob a Creative Commons Attribution 4.0 License. 


\title{
Terra indígena Foxá "aqui no cedro": passado e presente Kaingang na sociedade do Vale do Taquari-RS-BR ${ }^{1}$
}

\section{Resumo}

$\mathrm{Na}$ atualidade, os Kaingang constituem um dos mais numerosos povos indígenas do Brasil meridional, somando aproximadamente 38 mil pessoas, integrando a família linguística Jê Meridional. $\bigcirc$ objetivo deste estudo é identificar a importância do território para os Kaingang da terra indígena Foxá que se estabeleceram em área urbana da cidade de Lajeado-RS e seu modo próprio de territorialização. $\bigcirc$ aporte metodológico se debruça em fontes documentais e bibliográficas, que são analisadas a partir de teóricos da territorialidade, cultura e historicidade indígena. Salienta-se ainda que foram feitas visitas à terra indígena Foxá, bem como diálogos com os Kaingang. $O$ estudo apresenta aspectos alusivos dos indígenas e sua relação com o território em espaços urbanos, situação que concorre para conhecermos o jeito de ser Kaingang e os saberes relevantes para a sociedade não indígena.

Palavras-chave: Indígenas Kaingang. Espaços urbanos. Territorialidade. Vale do Taquari.

\section{Indigenous land Foxá "here at cedro": Kaingang past and present in the society of Taquari Valley-RS-BR}

\begin{abstract}
Currently the Kaingang is one of the most numerous indigenous people of southern Brazil, accounting for approximately 38 thousand individuals, being part of the linguist family Jê Meridional. The aim of this study is to identify the importance of territory for the Kaigang from the Indigenous Land Foxá which are settled in an urban area of the city of Lajeado, state of Rio Grande do Sul, and their own way of territorialization. The methodological approach focuses on documentary and bibliographical sources, which are analyzed from theorists of indigenous territoriality, culture and historicity. It is important to note that visits to the Indigenous
\end{abstract}

\footnotetext{
○ estudo insere-se no Projeto de Pesquisa "Identidades étnicas em espaços territoriais da Bacia Hidrográfica do Taquari-Antas-RS: história, movimentações e desdobramentos socioambientais" e no Projeto de Extensão "História e Cultura Kaingang em territórios da Bacia Hidrográfica do Taquari-Antas" e conta com auxílio financeiro do Centro Universitário Univates.
} 
Land Foxá and dialogues with Kaingang leaders were also carried out. The study presents allusive aspects of indigenous people and their relationship to their home territory in urban areas, a situation that helps us to know the Kaingang Way of Being, as well as making their memories and lessons noticeable for the non-indigenous society.

Keywords: Kaingang Indians. Urban spaces. Territoriality. Taquari Valley.

\section{Introdução}

Os Kaingang são pertencentes à família linguística Jê, integram o tronco linguístico Macro-Jê e ocupam áreas territoriais nos estados de São Paulo, Paraná, Santa Catarina e Rio Grande do Sul. No Brasil meridional, atualmente, constitui-se do grupo étnico indígena mais expressivo do ponto de vista demográfico, totalizando aproximadamente 38 mil pessoas (IBGE, 2012).

Desde os primeiros contatos com os colonizadores europeus, os Kaingang encontravam-se estabelecidos em tradicionais territórios localizados nas bacias hidrográficas dos rios Tietê, Feio, Aguapeí e Paranapanema (São Paulo); bacias hidrográficas dos rios Tibagi, Ivaí, Piquiri e Iguaçu (Paraná) e bacias hidrográficas entre os rios Iguaçu e Uruguai (em Santa Catarina). De acordo com Laroque (2000), durante o século XIX ainda ocupavam territórios entre as bacias hidrográficas dos rios Peperi-Guaçu e Santo Antônio (Misiones, na Argentina), bem como em territórios das bacias hidrográficas dos rios Sinos, Caí, Taquari, Jacuí e Uruguai (no Rio Grande do Sul), espaços de onde retiravam a sua subsistência, por meio da caça, pesca e coleta e vivenciavam as suas crenças e cultura.

No século XIX é que o projeto colonizador e seus mecanismos mais efetivos passam a atingir o território e a organização social Kaingang, pois a política do Império brasileiro voltava-se a explorar as áreas de planalto no sul do Brasil (Dornelles, 2009). Neste período, instigados pelo projeto colonizador do governo da província de São Pedro do Rio Grande do Sul, os Kaingang tiveram seus territórios invadidos pelos imigrantes alemães, italianos e seus descendentes e pela política oficial visando confiná-los em aldeamentos.

Em territórios da Bacia Hidrográfica Taquari-Antas, especificamente no espaço territorial que posteriormente passou a designar-se de Região Vale do Taquari, onde atualmente localiza-se a terra indígena Foxá, o conflito entre populações indígenas e colonizador intensificou-se a partir do projeto de ocupação do território durante o século XIX, atendendo à política do Estado nacional brasileiro (Vedoy, 2015). Na concepção Kaingang, as bacias hidrográficas e os rios que a constituem são tomados como divisores fronteiriços para delimitar territórios entre as diversas parcialidades ligadas por laços de parentesco e afinidades, e a transposição desses limites, seja pelos próprios grupos Kaingang ou pelos colonizadores, tende a acarretar conflitos guerreiros, como é o caso dos referidos em territórios da Bacia Hidrográfica Taquari-Antas (Laroque, 2000). 
objetivo do estudo é identificar a importância do território para os Kaingang da TI Foxá que se encontram estabelecidos em área urbana da cidade de Lajeado-RS e seu modo próprio de territorialização.

Como perspectiva teórica para análise dos dados pesquisados, embasamo-nos em autores como Seeger e Viveiros de Castro (1979), Little (1994), Tommasino (2000) e Laroque (2007) que estudam aspectos históricos das coletividades indígenas, traços culturais e concepções sobre a territorialidade indígena.

A metodologia constitui-se na análise de fontes documentais e bibliográficos, bem como pesquisa de campo com lideranças e demais moradores da TI Foxá. Elaborou-se diários de campo e também realizou-se entrevistas com os indígenas tendo como base um roteiro com questões semiestruturadas para as quais obtivemos, tanto o Termo de Anuência Prévia (TAP) das lideranças indígenas como o Termo de Consentimento Livre Esclarecido (TCLE) de cada Kaingang entrevistado. As entrevistas com os interlocutores indígenas foram registradas em áudio com o auxílio de uma máquina digital e posteriormente transcritas, com a opção de se respeitar, no decorrer do texto, as falas indígenas na língua portuguesa, pelo fato de trazer marcas da língua Kaingang e consequentemente expressar o próprio jeito de ser Kaingang.

Termos, conceitos e/ou categorias utilizados no trabalho que consideramos oportuno esclarecer são terra indígena, coletividade e grupo étnico. Tomando a Constituição Federal de 1988 e o sentido proposto por Seeger e Viveiros de Castro (1979), a terra indígena adquire uma dimensão de territorialidade repleta de características simbólicas e culturais; fala-se em coletividade pelo fato de os Kaingang serem um grupo étnico culturalmente diferenciado, conforme estudos de Eltz (2011) e Saldanha (2009), bem como o trabalho de Descola e Pálsson (2001), que informa que, diferentemente das sociedades ocidentais, orquestradas pelo paradigma judaico-cristão, as sociedade indígenas (o que também se aplica à cosmologia Kaingang) não fazem distinção entre o mundo humano e o não humano, isto é, todos são tratados no mesmo patamar, portanto, de forma coletiva; quanto a grupo étnico, nos baseamos em Barth (2000), que discute a autodeterminação étnica dos grupos, que podemos aplicar aos indígenas em estudo pelo fato de se reconhecerem etnicamente como Kaingang, categoria que determina seu "modo de viver".

\section{Territorialidade Kaingang: a luta pela terra}

As interferências ocorridas em territórios tradicionais Kaingang, sobretudo pelo estabelecimento de fazendas e colônias e os aldeamentos no Norte do Rio Grande do Sul, cujo objetivo consistiu em concentrar parcialidades Kaingang, como é o caso das lideradas pelos caciques Fongue, Nonoai e Braga no século XIX ou mesmo postos indígenas nas primeiras décadas do século XX, observados no mapa (Figura 1), não foi suficiente para o confinamento Kaingang. Isto porque estes indígenas costumavam sair destas áreas e percorrer seus tradicionais territórios, o que se intensifica principalmente a partir de meados do século $X X$, quando muitos Kaingang provenientes de Nonoai, Guarita, Votouro, Ligeiro, por exemplo, retornam e se territorializam em tradicionais espaços como é caso da cidade de Lajeado, localizada em áreas da Bacia Hidrográfica Taquari-Antas. 


\section{Figura 1 - Aldeamentos e postos indígenas no Rio Grande do Sul}

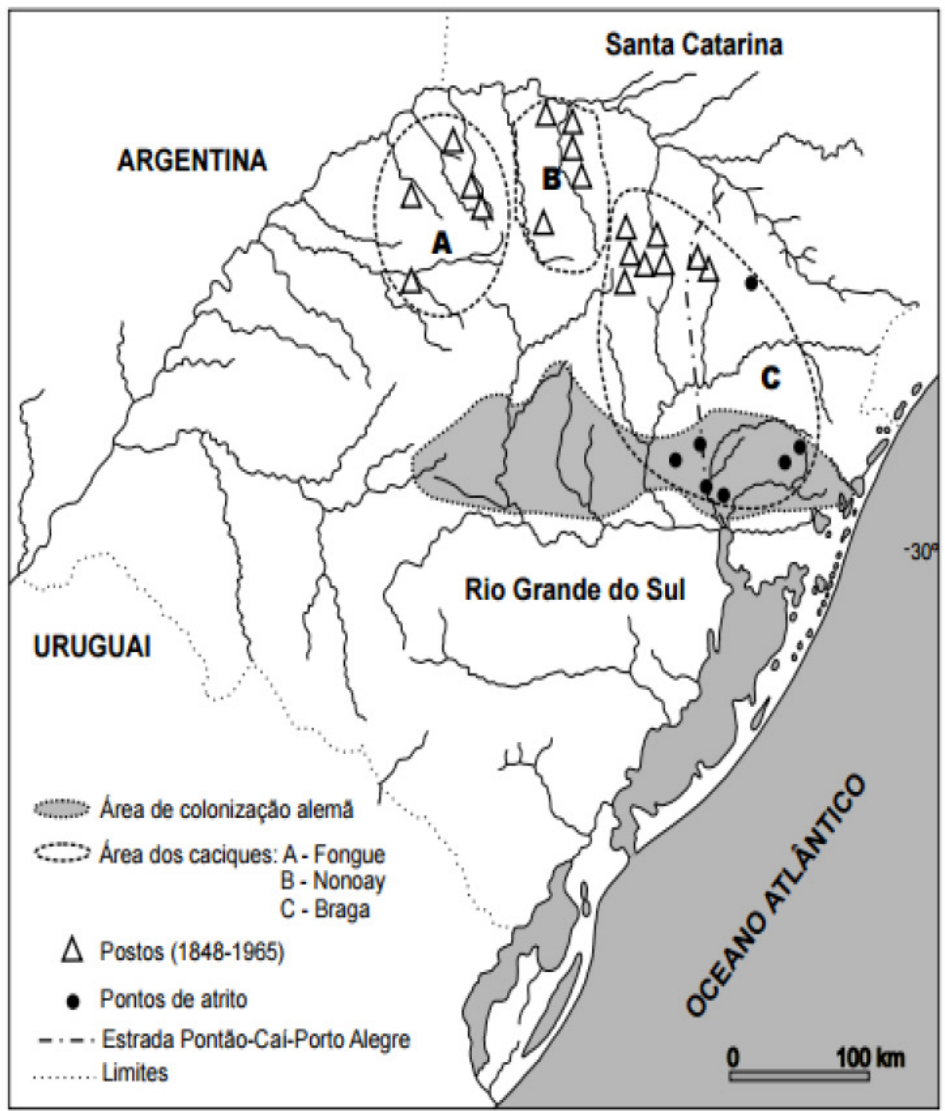

Mapa 1: localização das tribos Kaingang, dos pontos de atrito com a população nacional e dos pontos nos quais foram aldeados.

Sobre seus deslocamentos de Kaingang das terras indígenas de Guarita, Nonoai e Votouro, uma liderança Kaingang relata:

[...] aqui em Lajeado era um aldeia indígena Kaingang, né? Daqui, os índio saíam por Rio Pardo, pesca, caça [...] e agora tem em Lajeado essa outra aldeia, onde é que os índio Kaingang se acampavam ali no rio do Sino, e ficavam e ficavam, e virou um território indígena, e começaram querer desaldear os índio, né? A aldeia, por exemplo, pegaram todos os índio que conviviam aqui e uniram eles na aldeia de Nonoai, Guarita, Ligero, do cacique Doble. Tiraram dessa região em muito pouco tempo e então ficou essas aldeia que eles conviviam ali, e agora foram formada essas aldeias (EA1, 2011, p. 1, grifo nosso).

Nesse sentido, observa-se que, além da sobrevivência física e cultural, sobretudo no decorrer do século XX e XXI, os Kaingang intensificaram saídas das terras indígenas, localizadas no Norte do Rio Grande do Sul para ocupar outras partes do tradicional território presente na memória, com vista a trabalhar, sustentar a sua família e também para conseguir uma área para cultivo visando garantir a sustentabilidade da coletividade indígena. Situação que fica bastante evidente na pesquisa realizada com os Kaingang da terra indígena Foxá. 
Vale salientar que o século XX foi o período de contenção das territorialidades Kaingang às terras indígenas, por meio de coerção e tutela, órgãos indigenistas, como o Serviço de Proteção aos Índios e Localização dos Trabalhadores Nacionais (SPILTN), Serviço de Proteção aos Índios (SPI) e Fundação Nacional do Índio (Funai). No entender de Almeida (2015), a Constituição Federal do Brasil, promulgada em 1988, representa um momento singular para os povos indígenas no Brasil à medida que trouxe algumas inovações conceituais em relação às constituições anteriores e ao Estatuto do Índio de 1973. Assim, a Constituição de 1988 abandona a perspectiva "assimilacionista" nas quais o indígena era concebido como categoria transitória e se integraria à sociedade nacional brasileira.

A Constituição de 1988 foi a primeira a estabelecer um capítulo exclusivo aos direitos dos povos indígenas, sobretudo no artigo 231 que reconhece aos indígenas os direitos originários sobre as terras que tradicionalmente ocupam "o chamado indigenato, ou seja, o direito congênito de ordem imemorial que têm os indígenas sobre determinadas terras brasileiras", competindo à União demarcá-las, proteger e fazer respeitar todos os seus bens (Beckhausen, 2000, p. 60). Nas palavras de Almeida (2015, p. 56), temos:

Em 1988 o órgão indigenista nacional, a Funai, deixa de "tutelar" e passa a colaborar e assistir os povos indígenas no Brasil. $\bigcirc$ indígena passa a ter direito a sua carteira de identidade, como todo brasileiro, bem como autonomia de ir e vir sem a obrigatória chancela do órgão indigenista.

A partir deste marco constitucional, o estado do Rio Grande do Sul assume duas responsabilidades principais no que concerne às terras indígenas: a primeira é reconhecer e demarcar as terras indígenas conforme os limites definidos pelo critério da ocupação tradicional, isto é, de acordo com usos, costumes e tradições de cada povo. A segunda é proteger e fazer respeitar o usufruto exclusivo, aos índios, das riquezas naturais existentes no solo, nos rios e lagos das terras de ocupação tradicional (Liebgott; Bonin, 2013).

Considerando a demarcação de terras indígenas e o direito estabelecido na Constituição, perguntado sobre a importância para a coletividade Kaingang de ter seus territórios reconhecidos como terra indígena, o entrevistado informa:

Olha, pra nós, eu até calculo que através disso nós vamos ter mais - como é que eu vou dizer? - direitos pra usar nossa cultura, porque eu até tive casos aí que as nossas crianças não podiam apresentar nossa cultura fora. A nossa, o nosso pessoal, muitas vezes lá fora, no centro, tem vergonha de usar a cultura que tem. Aí, a gente sabe que tem nosso chão, tem nosso lugar perto do movimento e beneficio e um bom pouco também, já digo, de reconhecer onde é nosso, e um exemplo pros nossos filhos, netos, amanhã, depois, sabem que disso a gente nasceu, cresceu e que foi da terra, da cultura. Então, esse é um exemplo que a gente que dá a eles: que a gente não destruiu, que foi com isso que a gente viveu até hoje (EAa, 2015, p.2).

Entende-se que a luta pela terra se torna uma luta pela manutenção da identida- 
de étnica, baseada em uma cultura e memória em comum, pois as terras tradicionalmente ocupadas pelos Kaingang configuram-se como transmissão cultural, um direito originário e preexistente à ocupação ocidental, para a proteção efetiva do presente, que objetiva a garantia do futuro, no sentido de que essas terras estão para sempre destinadas a ser habitat permanente das populações indígenas. Na cosmovisão dos Kaingang das TI Foxá, o seu território é visto pela coletividade como um bem comum que tem força integradora de vida, de histórias e tradições.

Nesse sentido, segundo Dietrich (1995), é necessário compreender que o direito originário da terra se justifica pela ótica pretérita de ocupação indígena, ocupação esta que se deu antes mesmo da formação do Estado nacional brasileiro. Conforme Aresi (2008), atualmente as lutas da sociedade Kaingang estão pautadas na recuperação de seus territórios. É da conquista de seus espaços étnicos que depende a manutenção de suas identidades culturais. Nesse sentido, ainda referindo-se à importância de terem seus territórios reconhecidos como terra indígena, um Kaingang dos quais conversamos, informa:

Pois o indígena sabe o que é, o chão dele, ele sabe onde nasceu. Só que eu acho que é muito importante pra gente ser reconhecido fora. Não tem que ser reconhecido como acampamento indígena, mas sim uma terra indígena, né? Porque é direito de todos. Todos querem ter um cantinho, uma casa, e aqui ainda tem pessoas que falam que aqui é acampamento, tem pessoas de fora que conhece como acampamento, só que, na verdade, tinha que ser reconhecido como uma aldeia indígena, terra indígena (EAb, 2015, p. 2).

Tomando a fala em questão, entende-se que para os Kaingang o território indígena é considerado sagrado. É no território que os povos indígenas expressam sua cosmologia e seu próprio modo de ser, motivo pelo qual se observa os impasses, lutas e resistências do movimento indígena. Tratando-se dos Kaingang estas questões são formuladas e utilizadas pelo direito ancestral para legitimar a ocupação do tradicional território que the foi retirado pelo projeto colonizador. Tratando os conceitos de terra e território nas sociedades indígenas, Seeger e Viveiros de Castro (1979, p. 105) destacam:

Em termos econômico-Jurídicos, a terra, para as sociedades indígenas que conhecemos, não se definia nunca como mercadoria, objeto alienável de transações individuais. A propriedade [...] era investida no grupo local, e os direitos individuais ou familiares se exerciam sobre o trabalho na terra, sobre os frutos deste trabalho. Neste sentido a terra não podia ser definida como espaço homogêneo e neutro, mas como mosaico de recursos (tipos de solo, de matérias e seres ali encontrados etc.) desigualmente distribuídos por uma superfície sem existência conceitual nítida. $\bigcirc$ território, enquanto tal, podia ou não ser pensado como espaço fechado - isto dependia sobretudo das relações entre diferentes grupos tribais de uma mesma região, e também das formas econômicas prevalescentes. 
No entendimento do não indígena, a terra significa poder e riqueza, enquanto que para o indígena a terra tem sentido diferente. Nesse sentido, o relato do Kaingang Pedro Sales expressa o seguinte:

[... s significa uma mãe. A terra pra o índio é aquilo que dá alimento e água, igual a mãe que oferece alimento do seu copo para o seu filho. Enquanto que o branco já pensa diferente. $\bigcirc$ branco pensa que a terra para ele é um instrumento de gerar riqueza. Por isso, nossa ideia, nessa ótica é que ele não reconhece o seu irmão, o seu semelhante e discrimina cada vez mais aquele que não tem condições de enfrentá-lo, de correr com ele. [...] nós somos fruto desta humanidade que tem muito amor com a natureza e com a terra (Nonnenmacher, 2000, p. 79-80).

No decorrer dos séculos XIX e XX, a exigência dos Kaingang enquadra-se em um novo contexto histórico, no qual as demandas pela terra assumem um caráter de inserção no Estado nacional brasileiro por meio da afirmação e do reconhecimento de seus direitos. Segundo Luciano (2006) e Aquino (2009), o direito originário à terra está impregnado de laços culturais e históricos. $\bigcirc$ território indígena é sempre a referência à ancestralidade e a toda a formação cósmica do universo e da humanidade.

A ideia de pertencimento a um determinado território está relacionada à territorialidade que estabelece a relação entre o espaço e a coletividade indígena. Dessa forma, entende-se que os Kaingang produziram seus territórios de acordo com uma concepção própria de tempo e espaço. Ressalta-se também que a luta pela terra é permeada de aspectos simbólicos, que são vinculados à historicidade e à cultura da coletividade Kaingang.

\section{Indígenas Kaingang convivendo em espaço urbano}

A questão da presença indígena em contextos urbanos não é nova no cenário brasileiro. De acordo com o Censo Demográfico do Instituto Brasileiro de Geografia e Estatística (IBGE), o total de população indígena residente no território nacional em 2010 era de 896,9 mil pessoas, das quais aproximadamente $40 \%$ estavam em centros urbanos no país (IBGE, 2012).

De acordo com Baines (2001), Novo Hamburgo (2003) e Melo (2013), é possível constatar que nas últimas décadas do século XX houve uma crescente movimentação de indígenas para as cidades, visando obter melhores condições de sobrevivência envolvendo a sustentabilidade econômica como, por exemplo, a venda do artesanato e melhores condições de acesso a saúde e a educação, consumo de bens industrializados e até mesmo relações comerciais.

Nesse sentido, Andrade, Bellinger e Penteado (2013) enfatizam que, para os centros urbanos, a presença de povos indígenas resulta de dois processos: o crescimento das cidades, que alcançam as terras indígenas e as englobam na área urbana; e a movimentação dos indígenas para as cidades. Assim, em muitas situações, a vinda para as cidades coloca-se como o caminho para enfrentar a insegurança e as carências vivenciadas na terra indígena de origem. Isso é perceptível entre os Kaingang da TI Foxá de Lajeado, uma vez que fizeram as suas movimentações à cidade por terem sido estas erguidas em áreas pertencentes aos seus tradicionais territórios. Ilustra a questão um ofício relacionado aos subsídios antropológicos do Ministério Público Federal (MPF) de Lajeado que aponta: 
Há aproximadamente três décadas vem intensificando-se o fluxo de saída de famílias Kaingang das terras indígenas localizadas no planalto do Rio Grande do Sul, devido ao modo com que estão se manifestando os seus ciclos sócio-econômicos. É comum que essas famílias Kaingang se orientem para as proximidades das cidades de médio ou grande porte como é o caso de Porto Alegre e região metropolitana, alguns municípios da Serra gaúcha e vale do Taquari (Lajeado, 2008, p. 2).

De acordo com Rosado e Fagundes (2013), uma vez residindo na cidade, os indígenas redefinem o processo de territorialidade, manifesto ora pelos conflitos socioambientais, ora pelos vínculos estabelecidos com as áreas, que se apresentam como espaços de relações sociocosmológicas. Segundo Souza (2009), no Rio Grande do Sul, há presença de Kaingang circulando por cidades como, por exemplo, Porto Alegre, Caxias do Sul, São Leopoldo, Santa Maria, Pelotas, Lajeado, Estrela e Tabaí, é percebida como algo recente, como se os indígenas estivessem chegando agora ao Rio Grande do Sul, atraídos apenas pelos benefícios assistenciais e pela proteção tutelar do indigenismo promovido pelo Estado nacional brasileiro.

Seu Francisco Rockã, uma liderança falecida, mas que foi de extrema importância para a coletividade Kaingang, salienta que, quando chegaram à cidade de Porto Alegre, várias vezes ouviu os "brancos" falarem que lugar de índio é na aldeia e não na cidade. "Bem no fundo eles têm razão. Nossa origem não é da cidade. Mas eu pergunto: quem trouxe a cidade junto dos índios?" (Comin, 2008, p. 3). Tratando-se especificamente dos antepassados, bem como dos Kaingang que estamos analisando, temos:

Os deslocamentos Kaingang para a Bacia do Lago Guaíba parecem ser muito recuados no tempo. Aldeias atuais localizadas nas regiões hidrográficas Taquari-Antas, Caí e Sinos (como, por exemplo, as aldeias de Estrela e de São Leopoldo) indicam este desbordar desde o Planalto de populações Kaingang rumo ao sul e ao litoral. No passado pré-histórico, muitos assentamentos dos seus antepassados estão presentes nas regiões citadas. Muitos documentos históricos do final do século XIX e início do século XX atestam sua presença inegável na Bacia do Lago Guaiba, quando suas relações constantes e duradouras com os presidentes da Província e outras autoridades que os recebiam para tratar de seus interesses, além de outros motivos ligados à tradição, faziam-nos empreender longas expedições a pé por este território deles tão conhecido (Gehlen; Silva, 2008, p. 54).

A maneira como os Kaingang se reterritorializaram na cidade e a importância da comercialização do artesanato para a reprodução social indígena indica que os centros urbanos se tornaram uma extensão de seu território de origem de sobrevivência física e cultural.

No mapa hidrográfico (Figura 2), é possível identificarmos as oito terras indígenas que localizam-se em parte do tradicional território Kaingang em áreas urbanas do Rio Grande do Sul, como é o caso da TI Foxá analisada neste trabalho. Estes Kaingang circulam livremente por esse território, visitando parentes, colhendo material para o artesanato e sua comercialização. 


\section{Figura 2 - Localização das terras indígenas em contexto urbano}

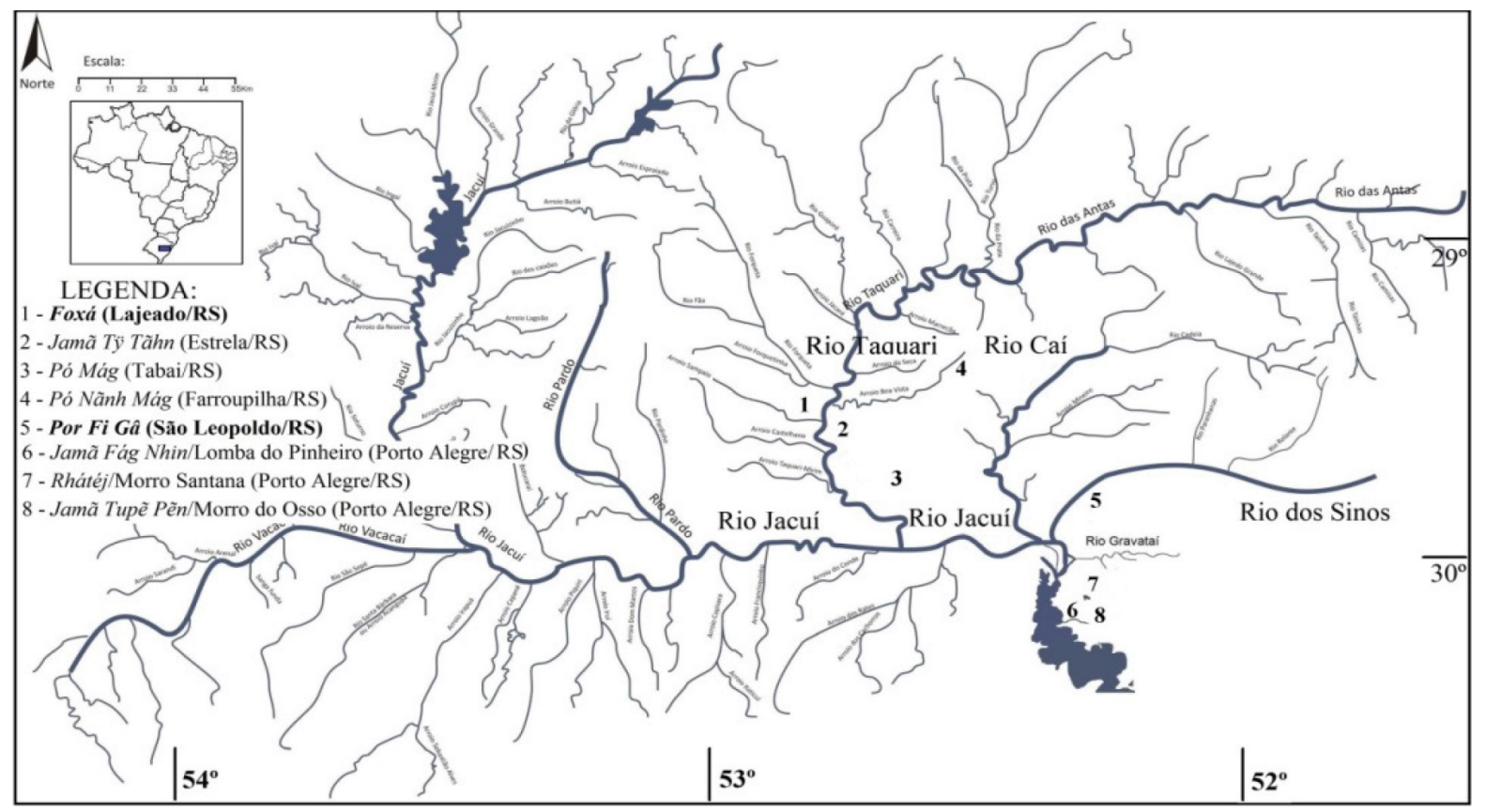

fonte: Acervo do Projeto História e Cultura Kaingang em Territórios da Bacia Hidrográfica Taquari-Antas. organização: Jonathan Busolli (2015), a partir do software I3GEO.

Na pesquisa sobre os Kaingang em contextos urbanos, percebe-se um (pre)conceito da sociedade não indígena. De acordo com Rosado e Fagundes (2013), parte da população não indígena externalizou desconhecer a presença de indígenas na cidade, pois o "indígena de verdade vive na floresta, caçando, pescando e coletando e que andam nus". Salienta-se que falas como "indígenas na cidade deixa de ser índio", "lugar do índio é no mato", são frutos de uma visão simplista, equivocada e preconceituosa, situação que vem ao encontro de Baines (2001), ao salientar que a questão indígena no Brasil é marcada por preconceitos historicamente enraizados e situações de relações sociais de dominação-sujeição altamente assimétricas entre "índios" e "brancos". Markus (2012), enfatiza que a presença de indígenas nas cidades nada mais é do que uma das tantas formas de adaptabilidade ao novo ambiente natural (modificado), social, econômico e político que se apresenta hoje para esses povos na região Sul.

Vivendo na cidade, os Kaingang configuram seus territórios, motivo pelo qual não somente busca a sobrevivência material, mas também se compreende como parte de uma rede simbólica e afetiva que dá sentido a sua existência. As tradições, por isso, não podem ser entendidas como inventadas, são fortalecidas nas movimentações em busca de uma vida melhor confluída pelo trabalho, educação e o uso do espaço como direito histórico de habitar a terra.

\section{Foxá - "aqui no cedro": a cidade de Lajeado entendida como território de origem Kaingang}

A coletividade Kaingang de Lajeado, localizada em contexto urbano, luta para reaver seus tradicionais territórios e manter seus costumes, mesmo vivendo em espaço urbano. A terra indígena Foxá, em Lajeado, se formou há aproximadamente 17 anos. Na língua Kaingang, esse nome significa "cedro" (fó sá - aqui no cedro), e atualmente é liderado pelo cacique João Vicente Garcia, com Jocelino na vice-liderança (História [...], 2017). 
As movimentações de retorno de Kaingang para a cidade de Lajeado intensificaram-se por volta do ano 2000, quando as primeiras famílias oriundas de Nonoai, e posteriormente de Serrinha, Votouro e Guarita se estabeleceram inicialmente às margens da rodovia estadual RS$130^{2}$, a 600 metros ao oeste do trevo de cruzamento com a rodovia federal BR-386, do lado esquerdo de quem se desloca para a cidade de Venâncio Aires (Rio Grande do Sul, 2009).

Aproximadamente quinze pessoas, entre jovens, adultos e crianças, viviam nas margens da rodovia estadual RS-130. Todos se instalaram no lugar com um objetivo comum: comercializar o artesanato para adquirir dinheiro para comprar alimentação, roupas e material escolar para os seus filhos (Os índios [...], 2002).

De acordo com as movimentações para os territórios de origem, quando perguntada pela motivação do grupo para se estabelecer em territórios da Bacia Hidrográfica Taquari-Antas, uma liderança da TI Foxá explica:

Isso que levou ao povo, porque a região [o Vale do Taquari] onde existem essas aldeias indígenas pequena são locais onde os nossos pais, nossos avós antigamente tinham seus assentamento e onde que às vezes os velho mesmo são os que trouxeram seus filho, seus neto pra esse local, acabaram se acostumando e acabaram ficando. E foi onde que, em algumas luta que foi lutado com até órgão do município, do estado, até os próprio órgão mesmo nos deram direito que era a terra indígena, onde o índio pudesse ter posse novamente (EA, 2015, p. 1).

Ainda referindo-se à cidade de Lajeado como um território Kaingang tradicional e levando em consideração a vinda para a cidade, um Kaingang narra o seguinte:

E porque esse lugar chamou a atenção e trouxe nós? E a gente vê que historicamente tem vestígio de índios, e era aqui do Jardim do Cedro. Então, é uma coisa assim, que onde eles viviam puxa o outro; parece assim um laço que puxa um o outro: onde ele 'tiver, vai puxando. E ali em Carazinho, a mesma coisa, sempre tem índio ali. Em Porto Alegre, pior, é um dos primeiro que teve aldeia e depois aqui. Farropilha era também; parece que puxou os Kaingang pra lá. Parece que tem uma coisa assim: vai lá, lá é de vocês. E porque todos os anos em que eu conheço Lajeado - faz nove anos que eu moro pra cá - e bem antes de eu chegar, já tinha gente morando aqui. Então, a gente se aprofundou pela história. A gente foi atrás e viu que a gente tá na direção certa, né? Ali, eu acho que a gente tem uma direção certa, e hoje tamos aí formando nossa aldeia, e teve pessoas boas, pessoas boas de fala, pessoas grandes, homens da lei viram que a gente tava no direito da gente em cima do que é nosso. Não tinha ninguém que tirasse nós, porque existia índio por aqui historicamente. Mas, graças a Deus, estamos aí lutando, conseguimos esse espaço (EB, 2012, p. 14, grifos nossos).

Além da venda do artesanato que foi uma motivação do grupo para se estabelecer neste centro urbano, outro fator importante para a movimentação dos Kaingang foi querer encontrar um lugar melhor para morar e consequentemente trabalhar e fazer sua moradia. Um Kaingang

2 A RS-130 é uma rodovia estadual do Rio Grande do Sul que liga a BR-386, na cidade de Lajeado-RS, à RS-129, na cidade de Encantado-RS. 
que em 2012 foi liderança da TI Foxá, explica que ele e sua mulher moravam na reserva de Nonoai, trabalhavam na lavoura e decidiram mudar para Lajeado em busca de melhores condições de sustentabilidade econômica (Lappe, 2012).

Em março de 2003, representantes da Promotoria de Justiça de Lajeado, Assistência Social e secretários municipais reuniram-se para discutir a situação em que se encontravam as famílias Kaingang acampadas às margens da RS-130, no município de Lajeado, em permanente risco e passando por carências. Nesta ocasião, foi sugerida a criação de um lugar onde os indígenas poderiam se estabelecer quando estivessem de passagem pela cidade. De acordo com o Termo de Audiência referente a assistência dos Kaingang, temos:

No entanto, pelos representantes do município, foi referido que não há área pública disponível para tanto nas mediações. A Funai se dispõe a fazer uma parceria com o município de Lajeado a fim de subsidiar com recursos materiais para atender as necessidades de manutenção da população indígena. Para tanto, o município irá fazer o levantamento das necessidades e encaminhar o pedido à Funai [...] de imediato ficou acertado que será acionada a Funasa para instalação de módulos sanitários no local onde se encontram acampados, sendo que a prefeitura se coloca à disposição para auxiliar para a efetivação da medida. Também será acionado o Daer a fim de ampliar a área de acostamento, criando uma espécie de refúgio para carros, facilitando assim a comercialização dos produtos de artesanato, sem expor a população indígena a riscos decorrentes do tráfego de veículos [...] (Lajeado, 2003, p. 1).

As três famílias, somando aproximadamente 20 pessoas, viviam em situação de precariedade as margens da RS-130. As habitações encontravam-se cobertas por lonas velhas, não dispunham de sanitários e energia elétrica, sendo que a saúde e higiene eram demasiadamente precárias. Visando resolver essa situação insalubre, em fevereiro de 2004, foi realizada reunião com órgãos públicos e representantes dos indígenas Kaingang com o objetivo de encontrar alternativas imediatas e duradouras para a melhoria das condições de vida dos indígenas acampados nas margens da RS-130.

Segundo Oliveira (2010), os Kaingang contaram com a ajuda do MPF, da Funai e de alguns segmentos da sociedade, tais como Conselho Tutelar, Conselho de Missão entre Índios (Comin) e Conselho Indigenista Missionário (Cimi). Em documento do MPF de Lajeado, encontramos a informação de que entre os problemas enfrentados pelos Kaingang estão a falta de água potável e banheiro, pois Lajeado naquele momento servia como um lugar de passagem dos Kaingang proveniente de várias áreas indígenas.

Nesse sentido, numa conversa conosco, a liderança Kaingang da terra indígena Foxá relatou que se lembra de quando vieram morar em Lajeado, há mais ou menos 10 anos, e que era difícil eles venderem artesanato e a gurizada trabalhar numa firma por causa do preconceito que havia em relação ao indígena (História [...], 2015b).

Em abril de 2004, novamente a Promotoria, Funai, Fundação Nacional da Saúde (Funasa) e secretários municipais se reuniram para decidir algumas providencias em relação aos indígenas Kaingang. Nesta ocasião, ficou definido que a Funasa seria a responsável por providenciar a instalação do ponto de água, junto ao acampamento às margens da RS-130, e substituir os dois tanques colocados pela Secretaria de Trabalho, Habitação e Assistência Social 
(STHAS). Também, ficou estabelecido que, na hipótese de haver a indicação de área para a instalação de um loteamento indígena, a Funasa se comprometeria com a instalação de um sistema de banheiro coletivo (Audiência, 2004).

Nesse mesmo período, foi apresentada uma área de aproximadamente $500 \mathrm{~m}^{2}$, localizada às margens da RS-130, distante $2 \mathrm{~km}$ do trevo de acesso, no sentido Lajeado-Cruzeiro do Sul, a qual seria cedida para o governo do estado alojar a comunidade indígena e, com isso, dissolver o acampamento até então existente. $\bigcirc$ Conselho Estadual dos Povos Indígenas (Cepi) ficou responsável por elaborar um croqui contento a forma de ocupação da área. Viabilizaria-se a instalação de quiosques às margens da RS-130, em ponto próximo ao trevo de acesso a cidade de Cruzeiro do Sul, a fim de permitir a comercialização do artesanato pelos indígenas (Audiência, 2004).

Da prefeitura de Lajeado, após muitas reuniões e discussões, os Kaingang receberam uma área de terra no bairro Jardim do Cedro para se instalar. As negociações para a instalação da terra indígena começaram em agosto de 2005. De acordo com a Lei n. 7.495, de 28 de dezembro de 2005, foi autorizado ao Poder Executivo conceder Cessão de Uso à Secretaria do Trabalho, Cidadania e Assistência Social do Estado do Rio Grande do Sul de uma fração de terras para a coletividade Kaingang de Lajeado. Esta cessão de terreno urbano será pelo prazo de cinco anos, com possibilidades de renovação por igual período (Lajeado, 2005).

Após conversas e acordos firmados entre os Kaingang e entidades como o MPF, a Funai e alguns segmentos da sociedade como o Conselho Tutelar, o Comin, o Cimi e a Prefeitura Municipal de Lajeado, em 11 de outubro de 2005, os indígenas conseguiram o direito de uso de uma área de terra de $525 \mathrm{~m}^{2}$ às margens da RS-130 no sentido da rodoviária de Lajeado à cidade de Cruzeiro do Sul, no bairro Jardim do Cedro. Esse lugar foi disponibilizado às famílias indígenas Kaingang por um Termo Administrativo de Cessão de Uso celebrado entre a Prefeitura Municipal de Lajeado e a Secretaria do Trabalho, Cidadania e Assistência Social do Estado do Rio Grande do Sul em 16 de janeiro de 2006 (Rio Grande do Sul, 2009).

Em decorrência de algumas pessoas representando gestores públicos e órgãos responsáveis e principalmente pela liderança indígena da época, o cacique Dilor Vaz Gatén, foi realizada nova reunião em março de 2007, sendo decidido a construção das casas para a data de 02 de abril de 2007, entretanto isto somente teve início em 09 de abril 2007.

Em abril de 2007, foram construídas no terreno oito casas para os Kaingang, com madeiras doadas pela Companhia Estadual de Energia Elétrica (Ceee) e a mão de obra e o restante do material foi fornecido pela prefeitura de Lajeado. Também foi construída uma unidade sanitária com três banheiros coletivos e dois tanques para lavar roupas. A água foi instalada com recursos da Funasa e a luz elétrica pelo programa Luz Para Todos, do governo federal (Rio Grande do Sul, 2009).

No momento em que foram definitivamente para o bairro Jardim do Cedro, os Kaingang resolveram nomear a terra indígena. Segundo relatos de alguns Kaingang, fizeram reunião e decidiram colocar o nome de Foxá. Quanto ao nome da terra indígena, um Kaingang afirma:

O nome da nossa aldeia aqui é Foxá, porque, historicamente, esse local do bairro a gente começou a analisar que - ele chamou muito a atenção da gente porque é um nome de uma madeira - a madeira é um remédio, eles serve pra todos. Que nem aquele dia que eu mostrei aquela árvore grande pra vocês, que tiraram foto, aquele lá; aquele serve pra muita coisa, aquilo vale ouro. Serve pra fazer remédio, 
às vez nossos velinhos derrubava a tábua pra fazer rodeado de casa - "tabinho", que eles dizem - pra fazer telhado da casa, né? Então, a gente entrou aqui em Lajeado, onde a gente foi localizado aqui nesta aldeia. E a gente não tinha nome; como aqui é Jardim do Cedro, a gente começou a pensar e botemo na cabeça Jardim do Cedro. Porque certamente, se nós entrevista os velinho mais moradores daqui, eles vão aprofunda, porque Jardim do Cedro tem também o significado deles, e botaram Jardim do Cedro. Pra nos, foi muito importante, e nós começamo a pensar e botemo Foxá, que é o nome já de uma madeira [cedro] que a gente pode preserva até anos e anos e anos, e aquela madeira vai ficá, vai tá marcado (EB, 2012, p. 5).

nome da terra indígena faz referência às árvores de cedro existentes no lugar. No entender dos Kaingang, essa árvore é de extrema importância, pois é considerada bem forte, e os Kaingang usam sua madeira para fazer casas e gamelas (artesanato Kaingang) colares com as sementes das frutas do cedro.

Segundo os Kaingang, o espaço onde agora se encontram foi uma conquista positiva, principalmente por se tratar de um lugar mais tranquilo, em que as crianças podem brincar livremente coletando frutas na pequena área de mata contígua ao terreno, onde nas proximidades podem coletar cipó e taquara para confeccionar o artesanato e comercializá-lo no centro da cidade de Lajeado (Rio Grande do Sul, 2009).

No momento atual, a terra indígena Foxá tem doze casas, onde residem aproximadamente dezessete familias, ou 96 pessoas, conforme se observa (Figura 3).

\section{Figura 3 - Vista parcial das casas da terra indígena Foxá}

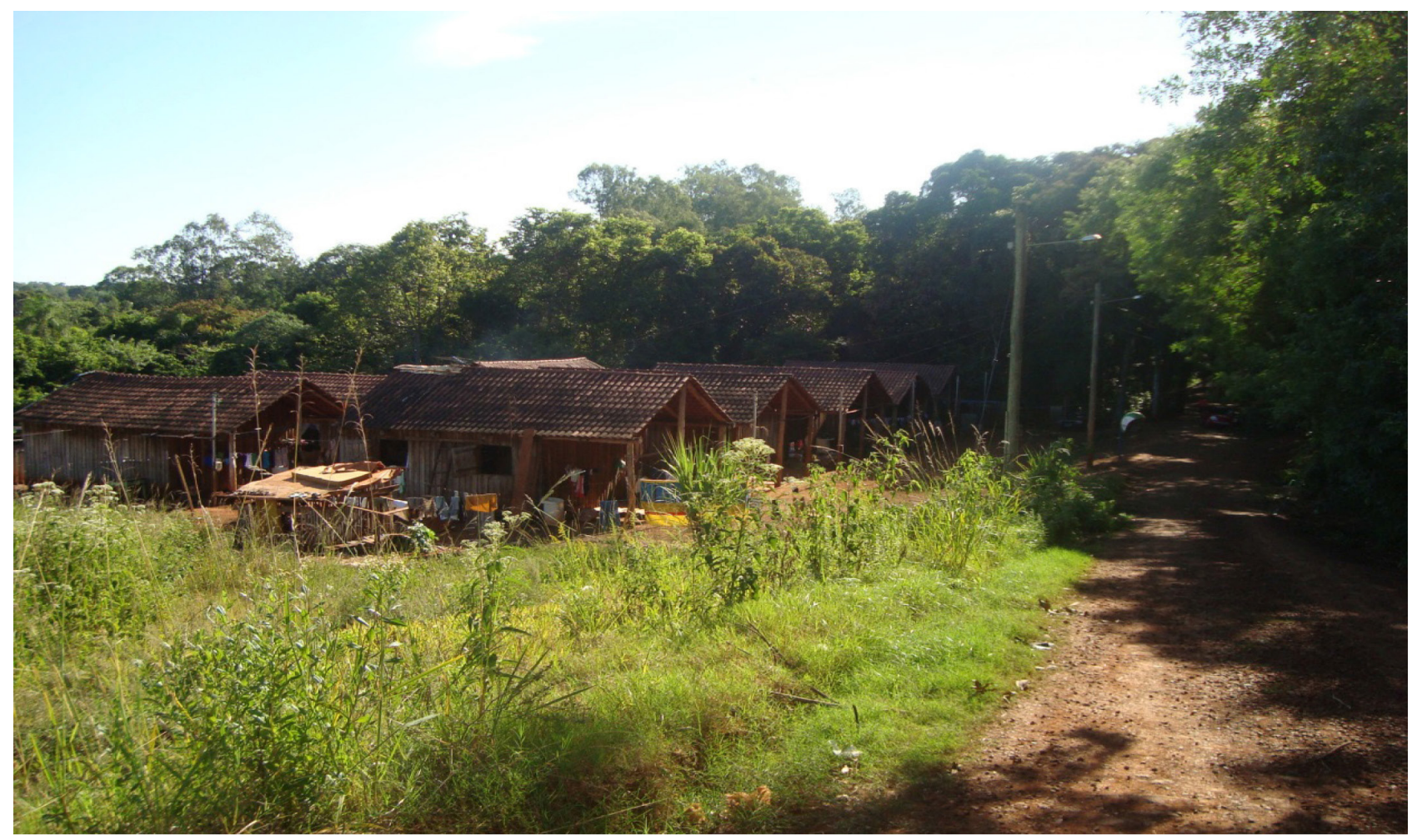

fonte: Acervo do Projeto de Extensão História e Cultura Kaingang em Territórios da Bacia Hidrográfica Taquari-Antas. Univates. 
A referida terra indígena conta com uma agente de saúde indígena. Em nossas pesquisas na Foxá, foi possível perceber que os Kaingang, além de trabalhar em indústrias locais, dão continuidade à sua tradição, têm uma horta coletiva na qual cultivam feijão, abóbora e moranga para auxiliar na alimentação da comunidade. Além disso, dedicam-se à confecção e à venda do artesanato, que faz parte da rotina diária do grupo (História [...], 2015a).

As crianças da TI Foxá frequentam a Escola Estadual Manoel Bandeira localizada na cidade de Lajeado há aproximadamente dez anos, sendo uma escola não indígena de ensino regular (Gonçalves, 2011). Em turno inverso do ensino formal, as crianças frequentam a escola indígenas, que está inserida dentro da terra indígena. Durante esse período, as crianças aprendem a língua e a escrita Kaingang com um professor bilíngue.

Em nossas pesquisas, percebe-se que o problema central é a falta de uma escola. Há uma previsão de construção da escola por parte do estado do Rio Grande do Sul (Lajeado, 2013), mas podemos observar que até o momento nada foi construído. A casa que era usada para ministrar as aulas teve problemas no telhado. Atualmente as crianças tem aula em uma pequena casinha da comunidade.

A TI Foxá, localizada no Vale do Taquari, surgiu em decorrência dos fenômenos recentes de urbanização, como por exemplo, o crescimento das cidades e a busca por melhores condições de sobrevivência. Além disso, podemos dizer que estes Kaingang têm um profundo respeito as suas terras de origem e compartilham com as outras terras indígenas um registro mitológico comum.

Esse prolixo caminho percorrido pelos Kaingang até a materialização da TI Foxá demonstra a persistência da coletividade, pautada na recuperação de seus tradicionais territórios e na luta por seus direitos, respaldados na Constituição. Sendo assim, salienta-se que o retorno para a cidade criou sentido e significados próprios, possibilitando comercializar o seu artesanato e manter seus traços étnicos e culturais.

\section{Considerações finais}

No percurso que realizamos junto aos Kaingang da TI Foxá de Lajeado, no Vale do Taquari, analisamos a importância das espacialidades sociais e territoriais para os Kaingang, a inserção deles na cidade e o seu modo próprio de territorialização, que garantem e rememoram 0 jeito de ser Kaingang.

A formação de novas terras indígenas em territórios da Bacia Hidrográfica Taquari-Antas se deve ao fato de no passado já terem habitado aquele lugar, e os seus antepassados terem enterrado ali seus umbigos. $\mathrm{Na}$ atualidade, as coletividades indígenas ocupam diferentes espaços, distribuídos praticamente em todo o território brasileiro.

A partir disso, podemos perceber que os Kaingang residentes em Lajeado na TI Foxá fizeram suas movimentações para a cidade porque estas foram erguidas em seus tradicionais territórios. Sendo assim, essa reocupação é justificável no sentido de possibilitar a sustentabilidade das coletividades, principalmente por meio de venda de artesanato, melhorias nas condições de saúde, educação e, sobretudo, representar uma continuidade cultural. 
Dessa forma, constatou-se que a coletividade Kaingang, mesmo inserida em áreas urbanas, mantém sua cultura por meio de seus conhecimentos tradicionais, valores e saberes que são perpassados de geração para geração. Nesse sentido, entende-se que a terra e o território são de grande valia para os Kaingang, não para a obtenção de riquezas, mas como espaço de sua produção e reprodução cultural.

Assim, a luta indígena pela terra é permeada de lutas simbólicas, que são vinculadas à historicidade e à cultura da coletividade Kaingang, uma vez que ser Kaingang consiste em portar uma história e uma origem em particular.

\section{Referências}

ALMEIDA, C. S. Tempo, memória e narrativa Kaingang no oeste catarinense: a tradição Kaingang e a proteção tutelar no contexto da transformação da paisagem na terra indígena Xapecó. Tese (Doutorado em História) - Universidade Federal de Santa Catarina, Florianópolis, 2015.

ANDRADE, L. M. M.; BELLINGER, C. K.; PENTEADO, O. C. Índios na cidade e políticas públicas. In: Comissão Pró-Índio de São Paulo (Org.). A cidade como local de afirmação dos direitos indígenas. São Paulo, 2013. p. 7-19.

AQUINO, A. Mü jé ha ("Vamos"): a fundação de aldeias Kaingang no litoral do Rio Grande do Sul. Tellus, Campo Grande, v. 9, n. 17, p. 111-136, 2009.

ARESI, C. Transformações culturais e território: o Kaingang da Reserva Indígena de Serrinha/RS. Dissertação (Mestrado em Geografia) - Universidade Federal do Rio Grande do Sul, Porto Alegre, 2008.

AUDIÊNCIA. Ata. Lajeado, RS: MPF, 18 fev. 2004.

BAINES, S. G. As chamadas "aldeias urbanas" ou índios na cidade. Revista Brasil Indígena, Brasilia, DF: Funai, v. 7, p. 15-17, nov./dez. 2001.

BARTH, F. Os grupos étnicos e suas fronteiras. In:

O guru, $\mathrm{o}$ iniciador e outras variações antropológicas. Rio de Janeiro: Contra Capa, 2000. p. 25-67.

BECKER, B. I. I. $\bigcirc$ que sobrou dos índios pré-históricos do Rio Grande do Sul. In: SCHMITZ, P. I. (Org.). Arqueologia do Rio Grande do Sul. 2. ed. São Leopoldo, RS: Unisinos, 2006. p. 126-147.

BECKHAUSEN, M. V. O reconhecimento constitucional da cultura indígena. Dissertação (Mestrado em Direito) - Universidade do Vale do Rio dos Sinos, Porto Alegre, 2000.

COMIN. CONSELHO DE MISSÃO ENTRE ÍNDIOS. Entrevistas com Kaingang de Porto Alegre e São Leopoldo. Povos Indígenas em espaços urbanos. Caderno da Semana dos Povos Indígenas do Comin. 2008. Disponível em: http://comin.org.br/ static/arquivos-publicacao/semana-dos-povos-2008-entrevistas-kaingang-porto-alegre-1207079439.pdf. Acesso em: 18 ago. 2015. 
DESCOLA, P.; PÁLSSON, G. Introducción. In: Naturaleza y sociedad: perspectivas antropológicas. México, DF: Siglo Veintiuno, 2001. p. 11-33.

DIETRICH, M. A. Os povos indígenas e o Estado brasileiro: traços de um massacre físico, cultural e jurídico. Cadernos do Comin, n. 4, p. 1-36, fev. 1995.

DORNELLES, S. S. A experiência vivida por imigrantes italianos e índios Kaingang na serra gaúcha (1875-1925): pioneiros em terras incultas e devolutas. Universidade Federal do Rio Grande do Sul, Porto Alegre, 2009. (Manuscrito.)

ELTZ, D. D. Corporalidades Kanhgág: as relações de pessoa e corpo no tempo e espaço Kanhgág. Dissertação (Mestrado em Antropologia Social) - Universidade Federal do Rio Grande do Sul, Porto Alegre, 2011.

GEHLEN, I; SILVA, S. B. (Org.). Estudo quantitativo e qualitativo dos coletivos indígenas em Porto Alegre e regiões limítrofes. Relatório final. Laboratório de Observação Social. Instituto de Filosofia e Ciências Humanas, Universidade Federal do Rio Grande do Sul, Porto Alegre, 2008.

GONÇALVES, L. M. C. Crianças indígenas Kaingang em escola não indígena: um estudo de caso envolvendo a Escola Estadual de Ensino Fundamental Manuel Bandeira, em Lajeado-RS. Monografia (Especialização em Supervisão e Gestão Educacional) - Centro Universitário Univates, Lajeado, 2011.

HISTÓRIA E CULTURA KAINGANG EM TERRITÓRIOS DA BACIA HIDROGRÁFICA TAQUARI-ANTAS. Projeto de extensão - pesquisa de campo na terra indígena Foxá, Lajeado-RS. Diário de Campo. Lajeado, RS: Univates, 13 mar. 2017.

Projeto de extensão - visita às terras indígenas Foxá e Pó M đg, Lajeado e Tabaí-RS. Diário de Campo. Lajeado, RS: Univates, 12 ago. 2015a.

Projeto de extensão - visita à terra indígena Foxá, Lajeado-RS. Diário de Campo. Lajeado, RS: Univates, 10 fev. $2015 b$.

IBGE. INSTITUTO BRASILEIRO DE GEOGRAFIA E ESTATÍSTICA. Censo Demográfico 2010: características gerais dos indígenas. Rio de Janeiro: 2012. Disponível em: ftp://ftp.ibge.gov.br/Censos/Censo_Demografico_2010/Caracteristicas_Gerais_dos_ Indigenas/pdf/Publicacao_completa.pdf. Acesso em: 15 maio 2015.

LAJEADO (Município). Parecer Memo. DOE/DAD/Seduc n. 330, de 8 de agosto de 2013. Departamento Administrativo. Divisão de Obras Escolares. Obras comunidades indígenas de Lajeado-RS. Lajeado, RS: MPF, 2013.

Parecer n. 1, de 27 de fevereiro de 2008. Procuradoria Regional da República da 4a Região. Parecer referente aos subsídios antropológicos relativos à possível construção de presídio estadual no município de Lajeado nas proximidades da comunidade indígena Kaingang neste mesmo município. Procedimento Administrativo n. 1.29.014.00000/200897. Lajeado, RS: MPF, 2008.

Lei n. 7.495, de 28 de dezembro de 2005. Lajeado, RS, 28 dez. 2005. (Fotocópia.) 
Termo de Audiência, 13 mar. 2003. Lajeado, RS, 13 mar. 2003. (Fotocópia.)

LAPPE, E. Natureza e territorialidade: um estudo sobre os Kaingang das terras indígenas Linha Glória-Estrela, Por Fi Gâ-São Leopoldo e Foxá-Lajeado. Monografia (Licenciatura em História) - Centro Universitário Univates, Lajeado, 2012.

LAROQUE, L. F. S. Fronteiras geográficas, étnicas e cultural envolvendo os Kaingang e suas lideranças no sul do Brasil (1889-1930). São Leopoldo, RS: Instituto Anchietano de Pesquisas, 2007. (Antropologia, 64.)

Lideranças Kaingang no Brasil meridional (1808-1889). São Leopoldo, RS: Unisinos, 2000. (Antropologia, 56.)

LIEBGOTT, R. A.; BONIN, I. T. Territorialidade e lutas pela garantia de direitos indígenas no Rio Grande do Sul. Justiça Federal do Rio Grande do Sul, Porto Alegre, v.1, n.1, p. 1-16, 2013. Disponível em: http://revistadigital.jfrs.jus.br/revista/index.php/revista_autos_e_baixas/article/download/13/12.Acesso em: 7 mar. 2018.

LITTLE, P. E. Espaço, memória e migração: por uma teoria de reterritorialização. Textos de história, Brasília, DF: UnB, v. 2, n. 4, p. 5-25, 1994.

LUCIANO, G. S. (Org.). O índio brasileiro: o que você precisa saber sobre os povos indígenas no Brasil de hoje. Brasilia, DF: Ministério da Educação, Secretaria de Educação Continuada, Alfabetização e Diversidade/Laced, Museu Nacional, 2006.

MARKUS, C. (Org.). Povo Kaingang: vida e sabedoria. São Leopoldo, RS: Comin, 2012. (Semana dos Povos Indígenas - 2012.)

MELO, J. G. Dimensões do urbano: o que as narrativas indígenas revelam sobre a cidade? Considerações dos Baré sobre Manaus-AM. Teoria e Cultura, Juiz de Fora, MG: UFJF, v. 8, n. 1, p. 115-126, 2013.

NONNENMACHER, M. S. Aldeamentos Kaingang no Rio Grande do Sul: século XIX. Porto Alegre: Ed. PUC-RS, 2000.

NOVO HAMBURGO (Município). Projeto Antropológico de maio de 2003. Projeto de etno-sustentabilidade e economia solidária na comunidade de índios Kaingang em São Leopoldo. Procedimento Administrativo n. 1.29.003.000003-2007 Apenso. Novo Hamburgo: MPF, 2007.

OLIVEIRA, M. D. Essa terra já era nossa: um estudo histórico sobre o grupo Kaingang na cidade de Lajeado. Monografia (Graduação em História) - Centro Universitário Univates, Lajeado, 2010.

OS ÍNDIOS têm consciência. Cruzeiro do Sul, Cidade, 2002, p. XX. In: Procedimento Adiministrativo n. ICP 1.29.001.000009/2003-49. DOCUMENTO do PF de Lajeado.

RIO GRANDE DO SUL. Secretaria da Agricultura, Pecuária, Pesca e Agronegócio. Diagnóstico da comunidade indígena Kaingang de Lajeado para subsidiar decisões sobre construção ou não de uma nova penitenciária no município de Lajeado. Lajeado, RS: MPF, 12 jun. 2009 
ROSADO, R. M.; FAGUNDES, L. F. C. (Org.). Presença indígena na cidade: reflexões, ações e políticas. Porto Alegre: Núcleo de Políticas Públicas para Povos Indígenas/ Hartmann, 2013.

SALDANHA, J. R. "Eu não sou pedra para sempre": cosmopolítica e espaço Kaingang no sul do Brasil meridional (2009). Dissertação (Mestrado em Antropologia Social) Instituto de Filosofia e Ciências Humanas, Universidade Federal do Rio Grande do Sul, Porto Alegre, 2009.

SEEGGER, A.; VIVEIROS DE CASTRO, E. B. Terras e territórios indígenas no Brasil. Revista Civilização Brasileira, Rio de janeiro, v. 12, n. 1-2, p. 101-114, 1979.

SOUZA, J. O. C. Um salto do passado para o futuro: as comunidades indígenas e os direitos originários no Rio Grande do Sul. In: SILVA, G. F; PENNA, R.; CARNEIRO, L. C. C. (Org.). RS índio: cartografias sobre a produção do conhecimento. Porto Alegre: Ed. PUC-RS, 2009. p. 270-284.

TOMMASINO, K. Território e territorialidade Kaingang: resistência cultural e historicidade de um grupo Jê. In: MOTA, L. T.; TOMMASINO K. (Org.). Uri e Wãxí: estudos interdisciplinares dos Kaingang. Londrina: Ed. UEL, 2000. p. 191-226.

VEDOY, M. I. B. Contatos interétnicos: sesmeiros, fazendeiros, imigrantes alemães e indígenas Kaingang em territórios das bacias hidrográficas do Taquari-Antas e Caí. Monografia (Graduação em História) - Centro Universitário Univates, Lajeado, 2015.

Entrevistas - Projeto de Extensão História e Cultura Kaingang em Territórios da Bacia Hidrográfica Taquari-Antas - Lajeado, RS: Univates

EA. Entrevistado A. Terra indígena Foxá. Lajeado-RS, 10 fev. 2015.

EAa. Entrevistado Aa. Terra indígena Foxá. Lajeado-RS, 28 ago. 2015.

EAb. Entrevistado Ab. Terra indígena Foxá. Lajeado-RS, 28 ago. 2015.

EAl. Entrevistado Al. Terra indígena Foxá. Lajeado-RS, 15 dez. 2011.

EB. Entrevistado B. Terra indígena Foxá. Lajeado-RS, 8 maio 2012. 